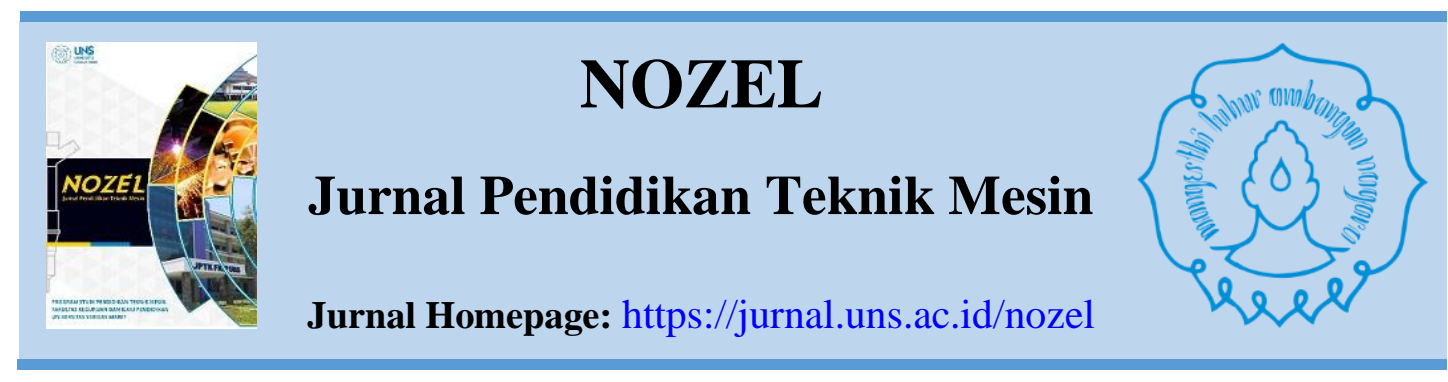

\title{
ANALISIS KUALITAS REPAIR WELDING CAST WHEEL ALUMINIUM MENGGUNAKAN METODE PENGELASAN OKSI-ASETILIN DENGAN PERLAKUAN PREHEATING DAN POST WELD HEAT TREATMENT
}

\author{
Aftoni Heri Septian Pamungkas ${ }^{1}$, Budi Harjanto ${ }^{1}$, Indah Widiastuti ${ }^{1}$ \\ ${ }^{1}$ Program Studi Pendidikan Teknik Mesin, FKIP, Universitas Sebelas Maret Surakarta \\ e-mail: Septyan22@gmail.com
}

\begin{abstract}
The aims of this research are to find out chemical composition, micro structure, the hardness level, and the strength impact of raw material and after welding using preheating and post weld heat treatment on cast wheel aluminum. Those data were analyzed using comparative descriptive method. The equipments used for measuring the chemical composition, microstructure, the hardness level, and the strength impact are as following: Spectrometer Metal Scan, Olympus Metallurgy Microscope, Vikers Hardness Tester and Charpy Tester. Based on the experiment results, it can be concluded that the chemical composition of the main constituent of cast wheel aluminum is 7,41\% Si, which can be categorized in the aluminum alloy AA4343 series. The experiment results showed a decrease in the extent of the microstructure of primary Si phase after welding. Si primary phase were spread well around the surface of $\alpha$-Al but the result Si after oxy-acetylene welding process with preheating and PWHT indicates that the primary Si phase is reducing so that the $\alpha$-Al phase is dominating. The hardness level on the welding result decreased from raw material amounted to $103.381 \mathrm{kgf} / \mathrm{mm}^{2}$ be $40.112 \mathrm{kgf} / \mathrm{mm}^{2}$ in the welding area and $44.378 \mathrm{kgf} / \mathrm{mm}^{2}$ in area Heat Affected Zone (HAZ). The strength impact number on welding area showed a slight increase from the raw material areas of 0.055 joules $/ \mathrm{mm}^{2}$ to the welding of 0.058 joule $/ \mathrm{mm}^{2}$.
\end{abstract}

Keywords: oxy-acetylene welding, Al-7,41\% Si alloys, cast wheels aluminum, preheating and PWHT

\section{A. PENDAHULUAN}

Peningkatan jumlah kendaraan bermotor berbanding lurus dengan peningkatan jumlah komponen pengganti (spare part). Komponen pengganti diperlukan untuk mengganti bagian kendaraan yang sudah tidak layak pakai atau rusak. Oleh karena itu, suatu Industri produsen kendaraan bermotor juga memproduksi komponen pengganti yang dibutuhkan agar masa pakai kendaraan lebih lama.

Salah satu komponen kendaraan yang berpeluang mengalami kerusakan dan perlu diganti adalah cast wheel atau biasa disebut velg. Velg merupakan bagian kendaraan 
yang berfungsi menopang roda agar dapat berputar dan juga sebagai penopang berat kendaraan. Kerusakan yang biasa terjadi pada velg kendaraan disebabkan adanya benturan saat kecelakaan maupun benturan pada jalan-jalan yang berlubang

Untuk menanggulangi rusaknya velg maka bisa dilakukan perbaikan dengan proses pengelasan. Proses pengelasan tersebut memungkinkan apabila nilai ketangguhan pada hasil pengelasan mendekati dengan nilai ketangguhan semula. Tujuannya untuk mengetahui komposisi kimia, struktur mikto, nilai kekerasan dan kekuatan impak pada cast wheel aluminium sebelum dan sesudah dilakukan pengelasan menggunakan metode pengelasan Oksi-asetilin dengan perlakuan preheating dan Post Weld Heat Treatment (PWHT).

Pengelasan oksi-asetilin merupakan pengelasan dengan gas yang dilakukan dengan cara membakar bahan bakar gas dengan $\mathrm{O}_{2}$ sehingga menimbulkan nyala api. Nyala api pada las oksi-asetilin ini menimbulkan suhu yang dapat mencairkan logam induk dan logam pengisi (Wiryosumarto dan Okumura, 2010: 33).

Aluminium merupakan logam ringan yang mempunyai sifat tahan korosi, mempunyai daya hantar listrik yang baik. Dengan penambahan $\mathrm{Cu}, \mathrm{Mg}, \mathrm{Si}, \mathrm{Mn}, \mathrm{Zn}$ maka akan menambah kekuatan mekaniknya. Berdasarkan unsur penambah tersebut maka Aluminum Association menggolongkan aluminium menjadi tujuh bagian, yaitu: 1. Al Murni, 2. Al-Cu, 3. Al-Mn, 4. Al-Si, 5. Al-Mg, 6. Al-Mg-Si dan 7. Al-Zn (Surdia, T. \& Saito, S: 1992).

\section{B. METODE}

Metode penelitian ini menggunakan metode eksperimen. Metode eksperimen merupakan metode untuk mencari hubungan sebab akibat dengan cara menganalisis kelompok yang diberi perlakuan dengan kelompok yang tidak diberi perlakuan

Populasi yang digunakan adalah cast wheel aluminium Isuzu Panther, sedangkan sampel penelitiannya dapat dilihat pada Gambar 1. berikut:

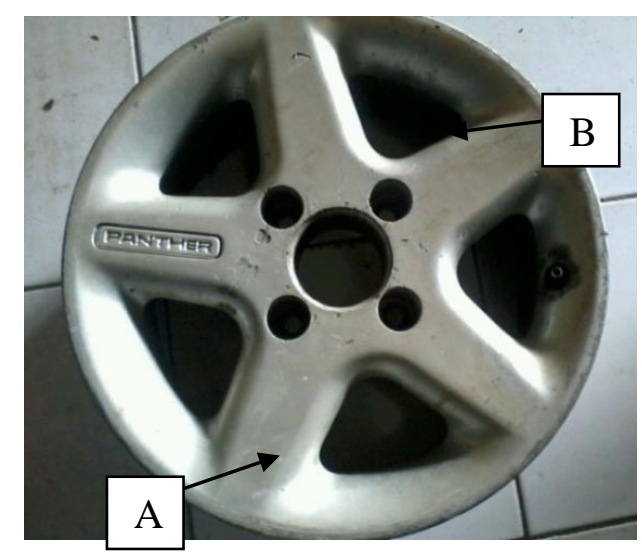

Gambar 1. Cast Wheel Aluminium Isuzu Panther

Keterangan:

A: Daerah Pengambilan Sampel untuk Pengujian Impak 
B: Daerah Pengambilan Sampel untuk Pengujian Komposisi Kimia, Pengujian Struktur Mikro dan Pengujian Kekerasan

Dalam penelitian ini menggunakan analisis deskriptif komparatif. Data yang diperoleh dari penelitian dianalisis dengan cara mendeskripsikan hasil pengamatan kekuatan spesimen dari penelitian yang telah dilakukan, kemudian membandingkan hasil pengamatan antara kedua spesimen.

\section{HASIL DAN PEMBAHASAN}

Hasil dan pembahasan pada penelitian ini meliputi: hasil uji komposisi kimia, pengamatan struktur mikro, hasil uji kekerasan dan hasil uji impak.

\section{Uji Komposisi Kimia}

Dari uji komposisi kimia, maka dapat dilihat bahwa cast wheel yang digunakan termasuk ke dalam paduan aluminium seri AA4343 seperti Tabel 1.

Tabel 1. Perbandingan Komposisi Kimia Cast Wheel Aluminium dengan Paduan Aluminium seri AA4343

\begin{tabular}{ccccc}
\hline No. & Unsur & $\begin{array}{c}\text { Kandungan } \\
\text { Kimia Cast } \\
\text { Wheel } \\
\text { Aluminium (\%) }\end{array}$ & $\begin{array}{c}\text { Komposisi } \\
\text { Paduan } \\
\text { Alumunium } \\
\text { seri AA4343 (\%) }\end{array}$ & Keterangan \\
\hline 1 & $\mathrm{Al}$ & 91,47 & $90.3-93.2$ & Sesuai \\
2 & $\mathrm{Si}$ & 7,41 & $6.8-8.2$ & Sesuai \\
3 & $\mathrm{Fe}$ & 0,235 & $<=0.80$ & Sesuai \\
4 & $\mathrm{Cl}$ & 0,155 & $<=0.25$ & Sesuai \\
5 & $\mathrm{Mn}$ & $<0,0200$ & $<=0.10$ & Sesuai \\
6 & $\mathrm{Zn}$ & 0,272 & $<=0.20$ & Kurang Sesuai, \\
\hline
\end{tabular}

\section{Uji Struktur Mikro}

Uji struktur mikro bertujuan untuk mengetahui bentuk, susunan, dan ukuran butir pada bahan. Pada pengujian ini pengamatan dilakukan pada permukaan spesimen yang telah dipoles dengan autosol dan dietsa dengan menggunakan nitrid acid $\left(\mathrm{HNO}_{3}\right)$ 2,5 ml, $\mathrm{HF} 1,5 \mathrm{ml} . \mathrm{HCl} 1,5 \mathrm{ml}$ dan 0,5 ml aquades selama 5 s/d 10 detik dengan mikroskop optic pembesaran 50 dan 100 kali. Pengamatan dilakukan pada bagian tanpa las, bagian las, HAZ dan juga pada base material.
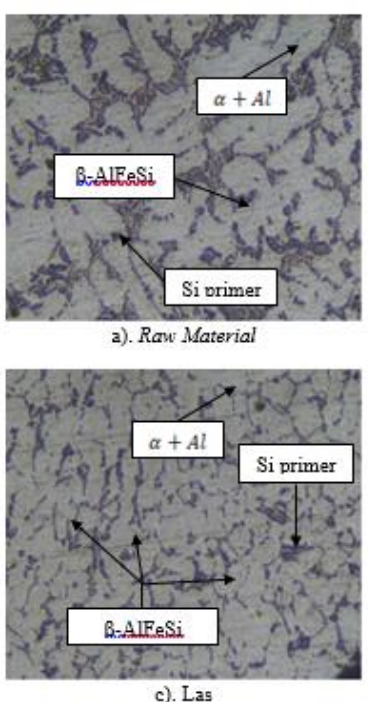
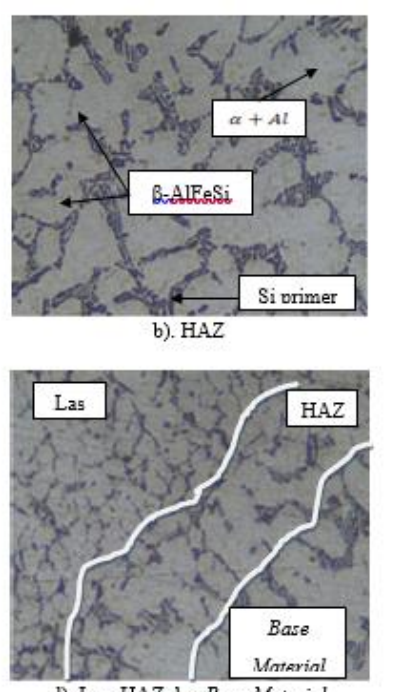

d). Las, HAZ dan Base Material
Gambar 2. Struktur Mikro Spesimen Raw Material dan Spesimen Las Hipoeutektik Al-7wt\%Si dengan Perlakuan Preheating dan PWHT Perbesaran 50x

Dari Gambar 2. dapat dilihat bentukbentuk fasa $\alpha+\mathrm{Al}$ dan juga fasa Si primer. Pada daerah raw fasa $\alpha+\mathrm{Al}$ (berwarna putih keabu-abuan) terlihat menggumpal 
besar dengan rongga $\mathrm{Si}$ primer (hitam gelap) didalamnya (Zeren: 2011).

Dari gambar 2. tersebut dapat dilihat bahwa terdapat perbedaan yang cukup signifikan pada perubahan luasan fasa. Luasan fasa $\alpha+\mathrm{Al}$ yang paling besar pada daerah las dan yang terkecil pada daerah raw. Luasan fasa Si primer terbesar pada daerah raw.

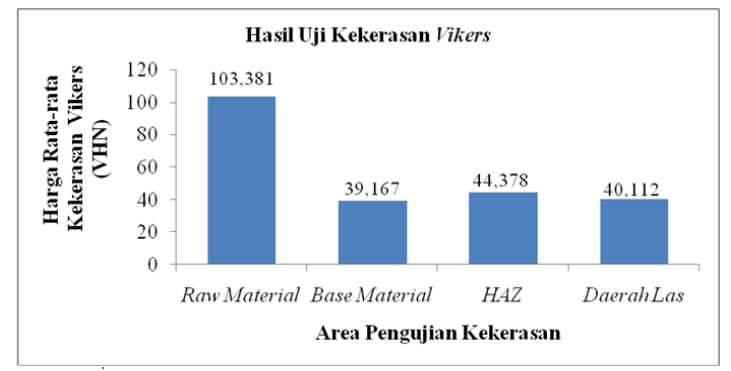

Gambar 3. Hasil Pengujian Kekerasan Vickers

Dari data hasil pengujian kekerasan Vickers pada Tabel 2. dan Gambar 3. Di atas dapat dilihat bahwa daerah yang mempunyai kekerasan tertinggi adalah raw material dengan kekerasan 103,81 VHN. Pada spesimen dengan mengalami penurunan harga kekerasan yang signifikan yaitu: pada daerah HAZ 44,378 VHN, sedangkan base material 39,167 VHN Penurunan kekerasan spesimen yang mengalami perlakuan preheating dan post weld heat treatment dikarenakan aluminium AA4343 termasuk jenis paduan aluminium yang tidak mempunyai kemampuan heat-treatable. Selain itu, penurunan kekerasan juga dapat terjadi karena munculnya fasa intermetalik. Fasa intermetalik timbul karena sifat unsur Fe yang mempunyai sifat susah padu dengan Al sehingga membentuk bagian sendiri. Fe yang tidak mencair bersama $\mathrm{Al}$ tersebut menimbulkan porositas dan mudah terkorosi (Taylor: 2012).

\section{Uji Impak}

Uji impak dilakukan dengan metode impak tipe charpy. Pengujian dilakukan dengan menggunakan beban pendulum sebesar $150 \mathrm{~J}$ dan panjang lengan pendulum $83 \mathrm{~cm}$ sudut awal sebelum pembebanan $(\alpha)$ sebesar $156^{\circ}$. Pengujian dilakukan terhadap cast wheel aluminium sebelum dan sesudah dilakukan pengelasan.

Tabel 3. Data Hasil Pengujian Kekuatan Impak

\begin{tabular}{cccccccc}
\hline $\begin{array}{c}\text { Jenis } \\
\text { Spes. }\end{array}$ & $\begin{array}{c}\text { No. } \\
\text { Spes. }\end{array}$ & $\begin{array}{c}\text { Sudut } \\
\alpha\left(^{\circ}\right)\end{array}$ & $\begin{array}{c}\text { Sudut } \\
\beta\left({ }^{\circ}\right)\end{array}$ & $\begin{array}{c}\text { Usaha } \\
(\mathrm{J})\end{array}$ & $\begin{array}{c}\text { Luas } \\
\left(\mathrm{mm}^{2}\right)\end{array}$ & $\begin{array}{c}\text { Harga Impak } \\
\left(\mathrm{J} / \mathrm{mm}^{2}\right)\end{array}$ & $\begin{array}{c}\text { Harga Rata-rata } \\
\text { Impak Charpy } \\
\left(\mathrm{J} / \mathrm{mm}^{2}\right)\end{array}$ \\
\hline \multirow{2}{*}{ Tanpa } & 1. & 156 & 151 & 4,73 & 80 & 0,059 & \\
Las & 2. & 156 & 151,5 & 4,23 & 80 & 0,053 & 0,055 \\
& 3. & 156 & 152 & 3,73 & 72 & 0,052 & \\
\hline \multirow{2}{*}{ Las } & 1. & 156 & 149 & 6,97 & 80 & 0,087 & \\
& 2. & 156 & 152 & 3,73 & 76 & 0,049 & 0,058 \\
& 3. & 156 & 153 & 2,74 & 72 & 0,038 & \\
\hline
\end{tabular}

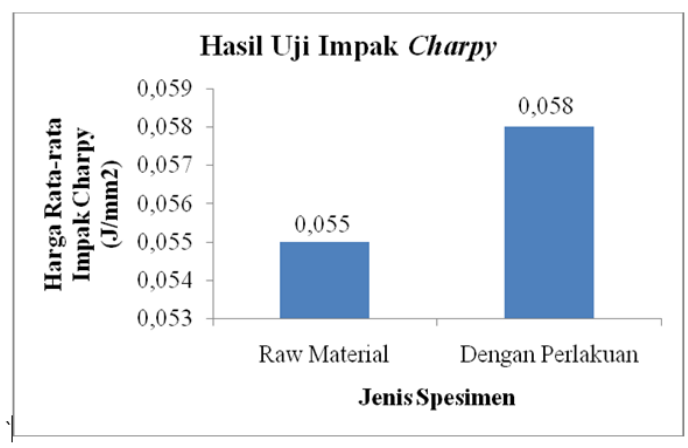

Gambar 3. Hasil Pengujian Impak 
Berdasarkan data yang diperoleh dari hasil penelitian yang dapat dilihat pada tabel 4.5. terdapat perbedaan nilai impak spesimen raw material dengan spesimen hasil lasan dengan preheating dan post weld heat treatment. Pada raw material sebesar $0,055 \mathrm{~J} / \mathrm{mm}^{2}$ dan pada spesimen hasil lasan dengan preheating dan post weld heat treatment $0,058 \mathrm{~J} / \mathrm{mm}^{2}$.

Ketangguhan impak ini sedikit mengalami kenaikan karena perbedaan perlakuan saat pengelasan dan treatment. Ketangguhan impak hasil lasan dengan preheating dan post weld heat treatment ini akan lebih meningkat apabila spesimen uji merupakan logam heat-treatable. Berdasarkan penelitian Isadare, et al (2012) menunjukkan adanya hubungan antara nilai kekerasan dan kekuatan impak. Dalam beberapa pengujian menunjukkan, apabila spesimen mengalami kenaikan nilai kekerasan, maka akan diikuti dengan penurunan kekuatan impak, dan apabila nilai kekerasan menurun maka kekuatan impak akan mengalami penurunan.

Berdasarkan pernyataan di atas dapat diambil kesimpulan bahwa perlakuan PWHT yang diberlakukan pada spesimen hasil pengelasan tidak mampu mengembalikan nilai kekerasan pada spesimen mendekati nilai kekerasan dari cast wheel utuh.

\section{PENUTUP}

\section{Simpulan}

1. Berdasar komposisi penyusun, cast wheel yang digunakan termasuk paduan Al-Si seri AA4343 yang memiliki sifat non heat-treatable.

2. Dari pengamatan struktur mikro pada spesimen raw material dan pada spesimen hasil repair welding (daerah base, HAZ, dan daerah las) terjadi perbedaan karena pengaruh panas yang diterima oleh tiap daerah. Peristiwa tersebut menyebabkan fasa-fasa $\alpha+\mathrm{Al}$ semakin menyebar, rapat dan dominan sedangkan fasa-fasa $\mathrm{Si}$ primer tetap mengelilingi fasa $\alpha+\mathrm{Al}$ akan tetapi dengan bentuk yang kecil memanjang.

3. Terdapat perbedaan nilai kekerasan (VHN) yang signifikan antara spesimen raw material dan spesimen hasil repair welding karena berkurangnya fasa $\mathrm{Si}$ primer pada raw material. Selain itu perbedaan nilai kekerasan karena timbulnya fasa intermetalik $(\beta-\mathrm{AlFeSi})$ yang terbentuk karena unsur Fe yang tidak larut dalam $\mathrm{Al}$ sehingga unsur $\mathrm{Fe}$ mempengaruhi terbentuknya korosi dan porositas pada paduan $\mathrm{Al}-\mathrm{Si}$ seri AA4343 tersebut.

4. Terdapat perbedaan nilai impak charpy yang tidak signifikan antara spesimen raw material $\left(0,055 \mathrm{~J} / \mathrm{mm}^{2}\right)$ dan 
spesimen hasil repair welding $(0,058$ $\mathrm{J} / \mathrm{mm}^{2}$ ) karena perlakuan panas yang dilakukan mengurangi tegangan sisa akibat proses pengelasan. Nilai impak akan lebih meningkat apabila spesimen yang digunakan merupakan logam heattreatable.

\section{DAFTAR PUSTAKA}

ASM International (2012), Aluminium and aluminiun alloy.

AWS. (2006). Structural Welding CodeSteel D1.1/D1.1

Pengetahuan Bahan Teknik. Jakarta: Pradnya Paramita.

Taylor, J.A. (2012). Iron-containing intermetallic phases in Al-Si based casting Alloys. Journal of Procedia Materials Science, 1: 19 - 33. Diperoleh pada 29 Juni 2016, dari www.sciencedirect.com

Surdia, T. \& Saito, S. (1992). Pengetahuan Bahan Teknik. Jakarta: Pradnya Paramita.

Wiryosumarto, H. Okumura, T. (2010). Teknologi Pengelasan Logam. Jakarta: Pradnya Paramita.

Zeren, M., Karakulak, E., \& Gumus, S. (2011). Influence of $\mathrm{Cu}$ Addition on Microstructure and Hardness of Near-eutectic Al-Si-xCu-alloys. The Scientific Research Project at Kocaeli Univercity, 6326 (11) 60917-5. Diperoleh pada 29 Juni 2016, dari www.sciencedirect.com 